\title{
COUPLED SEMICONDUCTORS AS PHOTO- ELECTROCHEMICAL CATALYST FOR WATER SPLITTING
}

\author{
${ }^{1}$ Denis ZABELIN, ${ }^{1}$ Anna ZABELINA, ${ }^{1}$ Anastasia TULUPOVA, ${ }^{1}$ Roman ELASHNIKOV, \\ ${ }^{1}$ Vaclav SVORCIK, ${ }^{1}$ Oleksiy LYUTAKOV \\ ${ }^{1}$ Department of Solid State Engineering, University of Chemistry and Technology, Prague, \\ Czech Republic, EU, Iyutakoo@vscht.cz
}

https://doi.org/10.37904/nanocon.2021.4342

\begin{abstract}
Hydrogen is a perspective "green» fuel that produces only water when consumed in a fuel cell. The main method for hydrogen production is electrochemical water splitting. However, the water electrolysis is a rather energy-consuming process. Alternative method of the overall water splitting is photo-enhanced electrolysis under light illumination. The founding or new, photo-and electro-catalytically active materials, able to increase the efficiency of water splitting is a hot topic of actual research. In recent years, 2D materials have been considered as very promising materials for the water splitting. In this work, a hybrid material consisting of 2D $\mathrm{WO}_{3}$-CdS coupled structure is created and introduced in water splitting process. Using the proposed design the high efficiency of hydrogen production can be potentially reached.
\end{abstract}

Keywords: Coupled semiconductors, 2D materials, water splitting, hydrogen production

\section{INTRODUCTION}

Hydrogen is a pure "green" fuel that produces only water when consumed in a fuel cell [1-4]. Today, governments and organizations are looking for alternative fuel sources for all types of energy consumers. While, for example, electric vehicles are generally seen as a response to the phasing out of fossil fuel vehicles, the application of hydrogen energy is increasingly proving to be a viable way of reducing carbon emissions $[5,6]$.

It is known that there is a large amount of hydrogen in water. Today, there are many ways to split water molecules into hydrogen and oxygen [7-10]. However, most of them take place under the application of electric current, which makes overall process less energy effective. Thus, due to the increased attention to the environment and the excessive consumption of fossil energy, the founding of alternative ways for total decomposition of water into hydrogen and oxygen is a very important field of research [11-14].

In recent years, 2D materials have been among the most promising materials for the water splitting process, since the sophisticated design of 2D materials makes it possible to increase the efficiency of the water splitting process $[15,16]$. However, for the creation and separation of the electron-hole pair in 2D materials, it is necessary to apply relatively high energy, by, for example, materials illumination with $\lambda<500 \mathrm{~nm}$. In order to be closer to full sunlight spectrum the NIR-light should be used.

In this work, a hybrid material consisting of a periodical metal electrode on the surface of which $\mathrm{WO}_{3}-\mathrm{CdS}$ hybrid flakes was created. The combination of $\mathrm{WO}_{3}$ and $\mathrm{CdS}$ semiconductors is one of the best for the photocatalytic formation of hydrogen and oxygen by water splitting based on the II-type semiconductors coupling. In turn, potential utilization of specific optical absorption from periodical metal electrode, which occurs due to excitation of collective electronic vibrations allows to introduced the apparent photo-contribution to water splitting efficiency $[17,18]$. 


\section{EXPERIMENTAL}

\subsection{Materials}

Sodium tungstate dihydrate ( $\geq 99 \%$ ), tetrafluoroboric acid (48 wt. \% in the water), cadmium chloride monohydrate (99.995\%), sodium sulphide nonahydrate $(\geq 99.99 \%)$ and deionized water were purchased from Sigma-Aldrich. Ethanol (p.a. 96\%) and methanol (p.a. 99.96\%) were purchased from Lachner.

\subsection{Sample preparation}

$\mathrm{WO}_{3}$ nanoflakes were prepared by mixing of sodium tungstate dehydrate with tetrafluoroboric acid solution with subsequent transfer to a Teflon autoclave and kept at $180{ }^{\circ} \mathrm{C}$ for 8 hours. The resulting product was centrifuged and purified twice with deionized water and twice with ethanol and was dried in an oven at $65{ }^{\circ} \mathrm{C}$ for 8 hours. $\mathrm{WO}_{3}-\mathrm{CdS}$ composite were prepared by adding consistently $0.1 \mathrm{M} \mathrm{CdCl} 2$ and $0.1 \mathrm{M} \mathrm{Na} 2 \mathrm{~S}$ solutions. The deposition of $\mathrm{WO}_{3}-\mathrm{CdS}$ suspension onto the surface of periodic electrode was carried out by spin-coating method.

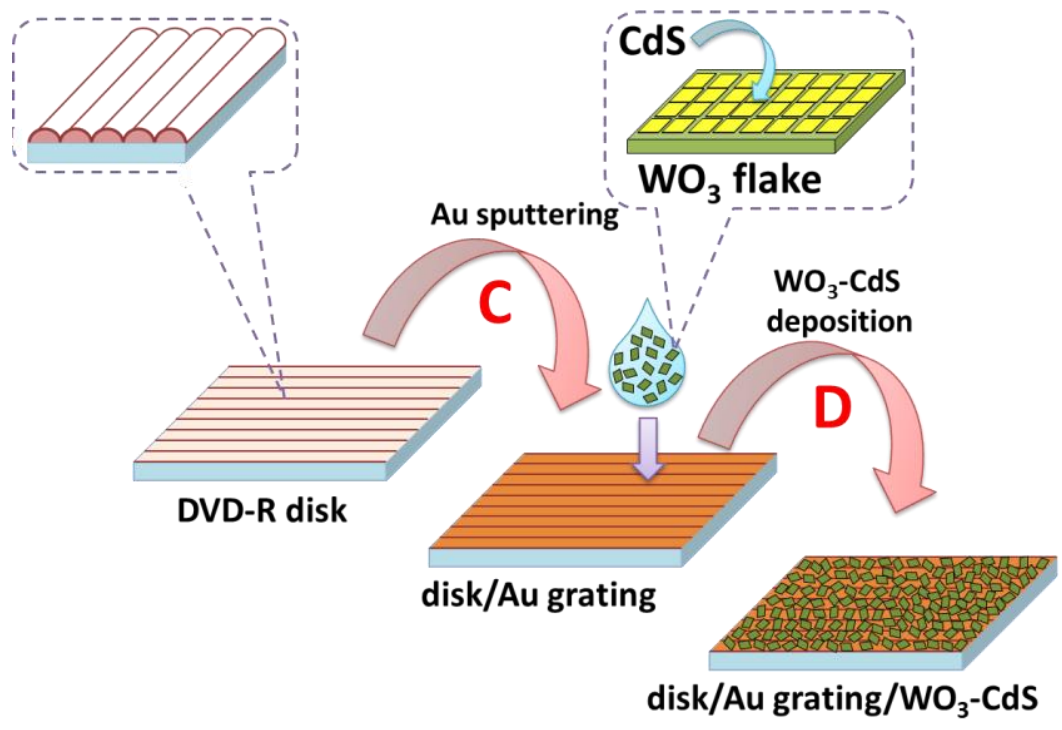

Figure 1 Schematic representation of sample preparation

\subsection{Measurement techniques}

X-ray diffraction microscopy spectra were recorded on a microXRD D8 Discover diffractometer for $30 \mathrm{~min}$ using $\mathrm{Cu}$ Ka radiation $(1.5405 \AA) 3$ at $30 \mathrm{~mA}$ and $40 \mathrm{kV}$. HRTEM measurements were performed using an EFTEM Jeol 2200 FS microscope (Jeol, Japan). X-ray photoelectron spectroscopy (XPS) was performed using an Omicron Nanotechnology ESCAProbeP spectrometer with a monochromated AI K Alpha X-ray source operating at $1486.6 \mathrm{eV}$. The energy resolution was $0.4 \mathrm{eV}$ for the survey study and $0.1 \mathrm{eV}$ for the highresolution XPS spectra measurements. The concentrations of elements were calculated in at.\% using the sensitivity factors provided by the manufacturer.

\section{RESULTS AND DISCUSSION}

Figure 2 shows $\mathrm{XRD}$ measurements results of $\mathrm{WO}_{3}$ nanoflakes and $\mathrm{WO}_{3}-\mathrm{CdS}$ composites. The $\mathrm{XRD}$ pattern of pure $\mathrm{WO}_{3}$ exhibits mostly a monoclinic phase. The main characteristic peaks acre located In the region of $23-24^{\circ}$. Looking at the XRD pattern of $\mathrm{WO}_{3}-\mathrm{CdS}$, the only independent peak of $\mathrm{CdS}$ at $33^{\circ}$ can be seen. Thus, $\mathrm{XRD}$ analysis confirmed the successful combination (coupling) of two semiconductors. 


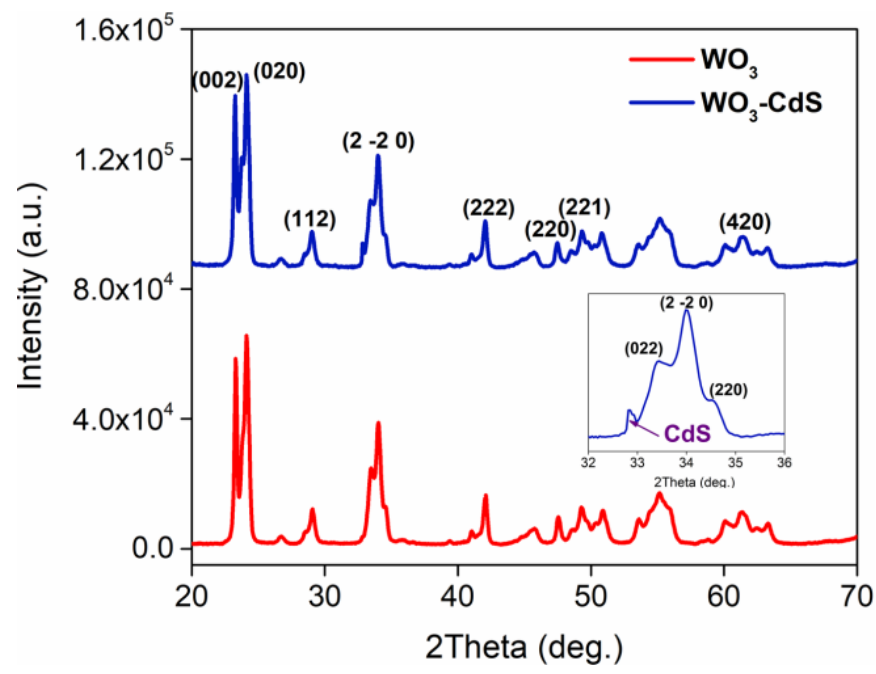

Figure $2 \mathrm{XRD}$ patterns of $\mathrm{WO}_{3}$ nanoflakes and $\mathrm{WO}_{3}-\mathrm{CdS}$ composite

On the Figure 3 the images from HRTEM measurements are presented. Figure $3 \mathrm{~A}$ confirms that $\mathrm{WO}_{3}$ flakes have thin 2D structure. After modification of $\mathrm{WO}_{3}$ nanoflakes by CdS (FigURE 3B) significant changes can be seen. Moreover, it is important to note that CdS particles are not occupy the entire surface area of the flakes, which is great for the overall water splitting process because both $\mathrm{WO}_{3}$ and $\mathrm{CdS}$ should be in contact with water for HER and OER processes to proceed.
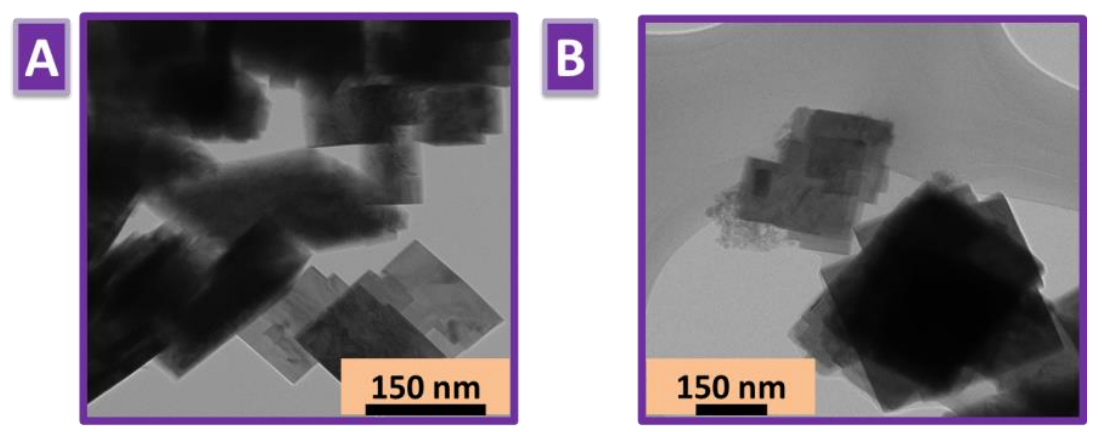

Figure 3 TEM images of pristine $\mathrm{WO}_{3}(\mathrm{~A}), \mathrm{WO}_{3}-\mathrm{CdS}$ composite $(\mathrm{B})$ and HRTEM image of $\mathrm{WO}_{3}-\mathrm{CdS}$ composite $(\mathrm{C})$

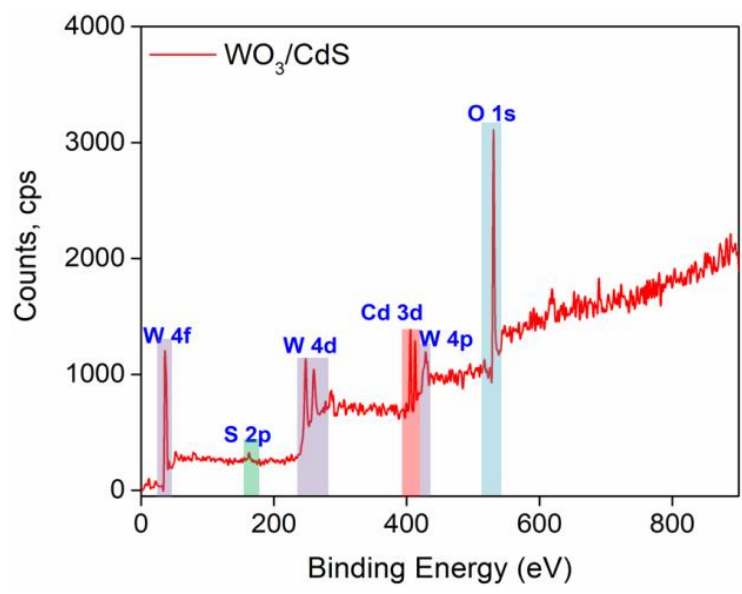

\begin{tabular}{|c|c|c|c|c|}
\hline & W, at\% & o, at\% & Cd, at\% & S, at\% \\
\hline $\mathrm{WO}_{3}$ & 29,39 & 70,61 & - & - \\
\hline $\mathrm{WO}_{3}$-CdS & 26,17 & 66,62 & 3,68 & 3,53 \\
\hline
\end{tabular}

Figure 4 Results of XPS analysis 
Figure 4 shows the results of XPS analysis. The main thing that should be note is that the elemental quantity relationship between $\mathrm{Cd}$ and $\mathrm{S}$ on the surface of $\mathrm{WO}_{3}$ is approximately $1: 1$. It means that the structure of cadmium sulfide doesn't have any defects and thus it has a possibility to product hydrogen from water.

\section{CONCLUSION}

In this work, a hybrid material consisting of a plasmon active gold lattice, on the surface of which are $\mathrm{WO}_{3}-$ CdS hybrid flakes, is created. The created materials represents an II-type coupled semiconductors. Moreover, both used materials are known to have the high efficiency in water splitting half-processes - OER and HER. The coupling of materials was confirmed using XRD, TEM and XPS techniques. Proposed structures can be considered as an interesting candidate for photo-electrochemically induced water splitting.

\section{ACKNOWLEDGEMENTS}

This work was supported by the project Internal Grant Agency UCT № A2_FCHT_2021_086

\section{REFERENCES}

[1] GHASEMZADEH, Kamran, ABBAS Aghaeinejad-Meybodi, and BASILE Angelo. Hydrogen production as a green fuel in silica membrane reactor: Experimental analysis and artificial neural network modeling. Fuel. 2018, vol. 222, pp. 114-124.

[2] HOSSEINI, S.E. and WAHID, M.A. Hydrogen production from renewable and sustainable energy resources: Promising green energy carrier for clean development. Renewable and Sustainable Energy Reviews. 2016, vol. 57, pp. 850-866.

[3] AHMED, A., AL-AMIN, A.Q., AMBROSE, A.F. and SAIDUR, R. Hydrogen fuel and transport system: A sustainable and environmental future. International journal of hydrogen energy. 2016, vol. 41, no. 3, pp. 13691380.

[4] ALI., I. Water photo splitting for green hydrogen energy by green nanoparticles. International Journal of Hydrogen Energy. 2019, vol. 44, no. 23, pp. 11564-11573.

[5] LASHGARI, M. and GHANIMATI, M. Supported polyoxometalates as emerging nanohybrid materials for photochemical and photoelectrochemical water splitting. Chemical Engineering Research and Design. 2020, vol. 162, pp. 85-93.

[6] LASHGARI, M. and GHANIMATI, M. An excellent heterojunction nanocomposite solar-energy material for photocatalytic transformation of hydrogen sulfide pollutant to hydrogen fuel and elemental sulfur: A mechanistic insight. Journal of colloid and interface science. 2019, vol. 555, pp.187-194.

[7] $\mathrm{CHI}$, J. and $\mathrm{YU}, \mathrm{H}$. Hierarchical coral-like $\mathrm{FeNi}(\mathrm{OH})_{x} / \mathrm{Ni}$ via mild corrosion of nickel as an integrated electrode for efficient overall water splitting. Chinese Journal of Catalysis. 2018, vol. 39, no.3, pp. 390-394.

[8] VINCENT, I. and BESSARABOV, D. Low cost hydrogen production by anion exchange membrane electrolysis: A review. Renewable and Sustainable Energy Reviews. 2018, vol. 81, pp. 1690-1704.

[9] NGUYEN, T., ABDIN, Z., HOLM, T. and MÉRIDA, W.. Hydrogen costs from water electrolysis at high temperature and pressure. Energy Conversion and Management, 2019, 200, p. 112108.

[10] KIM, J., JUN, A., GWON, O., YOO, S., LIU, M. et al. Hybrid-solid oxide electrolysis cell: A new strategy for efficient hydrogen production. Nano Energy. 2018, vol. 44, pp. 121-126.

[11] NALDONI, A., AltOMARE, M., ZOPPELlARO, G., LIU, N., KMENT, S., ZBOŘIL, R. and SCHMUKI, P. Photocatalysis with Reduced $\mathrm{TiO}_{2}$ : From Black $\mathrm{TiO}_{2}$ to Cocatalyst-Free Hydrogen Production. ACS catalysis. 2018, vol. 9, no. 1, pp. 345-364.

[12] WANG, M., ZUO, Y., WANG, J., WANG, Y., SHEN, X., QIU, B., CAI, L., ZHOU, F., LAU, S.P. and CHAI, Y. Remarkably Enhanced Hydrogen Generation of Organolead Halide Perovskites via Piezocatalysis and Photocatalysis. Advanced Energy Materials, 2019, vol. 9, no. 37, p. 1901801.

[13] BHARATVAJ, J., PREETHI, V. AND KANMANI, S. Hydrogen production from sulphide wastewater using Ce $\mathrm{C}^{3+}-$ $\mathrm{TiO}_{2}$ photocatalysis. International Journal of Hydrogen Energy. 2018, vol. 43, no. 8, pp. 3935-3945. 
[14] YE, L. and WEN, Z. ZnIn $\mathrm{S}_{4}$ nanosheets decorating $\mathrm{WO}_{3}$ nanorods core-shell hybrids for boosting visible-light photocatalysis hydrogen generation. International Journal of Hydrogen Energy. 2019, vol. 44, no. 7, pp. 37513759.

[15] LOW, J., CAO, S., YU, J and WAGEH, S. Two-dimensional layered composite photocatalysts. Chem. Commun. 2014, vol. 50, pp. $10768-10777$

[16] LIN, L., OU, H., ZHANG, Y. and WANG, X. Tri-s-triazine-Based Crystalline Graphitic Carbon Nitrides for Highly Efficient Hydrogen Evolution Photocatalysis. ACS Catalysis. 2016, vol. 6, no. 6, pp. 3921-3931.

[17] ZABELINA, A., ZABELIN, D., MILIUTINA, E., LANCOK, J., SVORCIK, V., CHERTOPALOV, S. and LYUTAKOV, $O$. Surface plasmon-polariton triggering of $\mathrm{Ti}_{3} \mathrm{C}_{2} \mathrm{~T}_{x} \mathrm{MXene}$ catalytic activity for hydrogen evolution reaction enhancement. Journal of Materials Chemistry A. 2021, vol. 9, no. 33, pp. 17770-17779.

[18] GUSELNIKOVA, O., TRELIN, A., MILIUTINA, E., ELASHNIKOV, R., SAJDL, P., POSTNIKOV, P., KOLSKA, Z., SVORCIK, V. and LYUTAKOV, O. Plasmon-induced water splitting-through flexible hybrid 2D architecture up to hydrogen from seawater under NIR light. ACS Applied Materials \& Interfaces. 2020, vol. 12, no. 25, pp. 2811028119. 